\section{Diagnosis and treatment of celiac disease}

\author{
LM Sollid $^{1}$ and KEA Lundin ${ }^{1,2}$
}

The understanding of the pathogenesis of celiac disease has made huge advances in recent years. The disease is caused by an inappropriate immune response to dietary gluten proteins. This immune response is controlled by $\mathrm{CD}^{+} \mathrm{T}$ cells in the lamina propria that recognize gluten peptides in the context of disease predisposing HLA-DQ2 and HLA-DQ8 molecules. ${ }^{1,2}$ These $T$ cells are specific for proline- and glutamine-rich gluten peptides that are resistant to proteolysis and that have been become deamidated by the enzyme transglutaminase 2 (TG2). Strikingly, celiac disease patients produce antibodies to this same enzyme when exposed to dietary gluten. Here we discuss how the new insight in the pathogenesis has lead to development of new diagnostics and nourished research into novel treatments.

\section{DIAGNOSTICS}

\section{Clinical aspects}

Celiac disease is a frequent disorder ( $1 \%$ prevalence) in populations of mainly Caucasoid descent. The disease develops at all ages, and most patients are diagnosed in adolescence. The disease is caused by an abnormal immune response to gluten proteins of wheat, rye, and barley. Current treatment is life-long elimination of gluten from the diet. There is increased morbidity and mortality associated with celiac disease but less so than previously thought. Treatment with gluten-free diet appears to reduce these risks.

Celiac disease has a diverse clinical picture ranging from tangible symptoms such as malabsorption, diarrhea, weight loss, and osteoporosis to vaguer symptoms such as iron and folic acid deficiency, arthralgia, fatigue, and abdominal discomfort. ${ }^{3}$ Celiac disease often presents without diarrhea, and celiac disease patients may even be obese. Asymptomatic patients can be found. Thus, the disease is impossible to diagnose on clinical grounds alone. The diagnostic workup is performed with a number of tests, of which many have immunological basis.

\section{Intestinal biopsy}

It is generally agreed that a diagnosis of celiac disease can only be made when the small intestinal morphology shows intraepithelial lymphocytosis, infiltration of the lamina propria with $\mathrm{T}$ cells and plasma cells, villous atrophy, and crypt hyperplasia $^{3}$ (Figure 1). The staging of mucosal changes suggested by Marsh is now widely used. It was earlier considered that at least partial villous atrophy (Marsh 3A) should be present for the diagnosis, but many now consider even the slightest changes (Marsh 1) compatible with active celiac disease. Importantly, when the mucosal changes are discrete, it is important to take clinical signs, serology as well as morphology into account. ${ }^{4}$

The intestinal biopsies are nowadays invariably taken by gastroduodenoscopy, but often this is performed with insufficient numbers and size of the biopsies. At least four biopsies should be taken, as the typical celiac lesions can be patchy. Proper histological interpretation by the pathologist is another important issue. Immunohistochemistry, which can demonstrate T cells expressing the $\gamma / \delta$ $\mathrm{T}$-cell receptor, is rarely used in clinical practice.

\section{Antibody detection}

Serological tests are key instruments for detection of celiac disease. ${ }^{3}$ Untreated celiac patients typically have increased immunoglobulin A (IgA) and immunoglobulin G (IgG) antibodies to wheat gluten and to the autoantigen transglutaminase 2 (TG2). ${ }^{5}$ Notably these antibodies disappear when the patients are commencing the gluten-free diet. Before TG2 was identified as the target for the autoantibodies in celiac disease, the so-called endomysium test based on immunofluorenscence staining of tissue substrates was used for the detection of these antibodies. The endomysium test is laborious and ELISA-based tests using recombinant human TG2 as antigen are now preferred. ELISA-based tests are also predominantly used for the detection of antibodies to the gluten subcomponent gliadin. IgA antibodies to both gliadin 


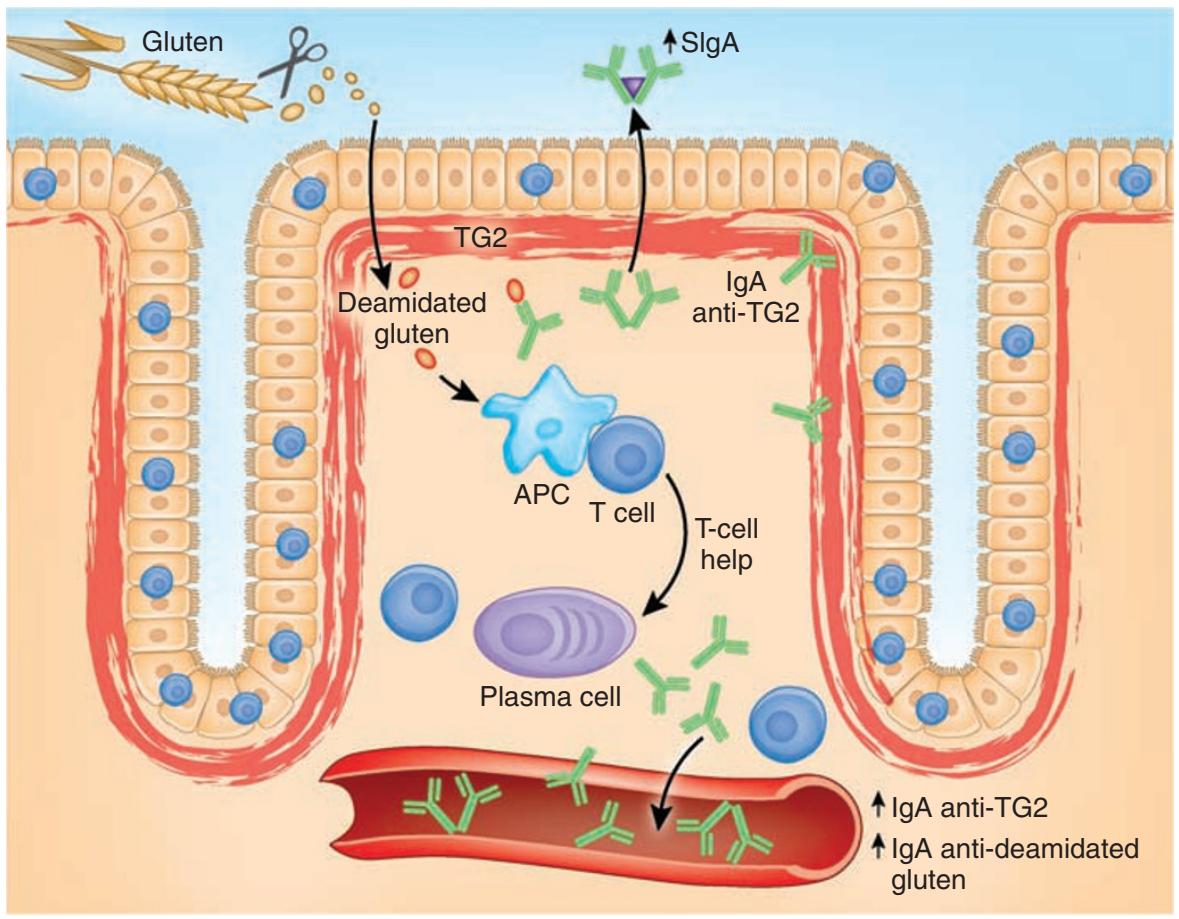

Figure 1 The established celiac lesion shows a complex interplay of inflammatory changes, and the typical morphological features including increased numbers of intraepithelial lymphocytes (IELs), decreased enterocyte height, villous atrophy, and crypt hyperplasia. There is increased density of activated $T$ cells and plasma cells in the lamina propria. The driving antigen of the process, gluten, is presented by antigen-presenting cells (APCs) in the lamina propria to CD4 ${ }^{+}$ T cells after it has been deamidated by transglutaminase 2 (TG2). There is increased local production of antibodies. Immunoglobulin A $(\lg A)$ antibodies are secreted to the gut lumen as secretory $\lg \mathrm{A}(\mathrm{S} \lg \mathrm{A})$, and antibodies spill over into the blood. Antibodies reactive with TG2 and deamidated gluten are typical of active celiac disease. The IgA anti-TG2 antibodies which react with extracellular TG2, form immune complexes that are localized just beneath the epithelium. The epithelial compartment shows several features of innate immunity with epithelial expression of IL-15 and activation of intraepithelial T cells expressing natural killer (NK) cell receptors such as NKGD2 and NKG2C.

and TG2 have higher disease specificities than the corresponding IgG antibodies. The detection of IgG antibodies to both these antigens is thus of little clinical value except in patients with IgA deficiency. This disorder is overrepresented among celiac disease patients. Measurement of total IgA should hence be included in the workup of celiac disease. If IgA deficiency is diagnosed, measurement of IgG antibodies to TG2 and gliadin should be performed.

It has been reported that production of IgA endomysial (anti-TG2) autoantibodies and gluten-dependent symptoms may occur in individuals with HLA types typical of celiac disease even in the absence of clear morphological changes. ${ }^{6}$ This observation has lead to the question whether intestinal biopsy should continue to be the gold standard for diagnosing celiac disease. $^{7}$
TG2 is an enzyme with many functions, and it is directly involved in celiac disease pathogenesis by modifying gluten peptides in a process where glutamine residues are deamidated to glutamic acid. The deamidated peptides bind better to the HLA-DQ2 and HLA-DQ8 molecules, and the intestinal $T$ cells of celiac disease patients preferentially recognize such deamidated gluten peptides. ${ }^{1}$ Immune recognition of deamidated gluten peptides does not only apply to T cells but to B cells as well. ${ }^{8,9}$ Serum tests for IgA antibodies to deamidated gliadin peptides show specificity and sensitivity for celiac disease quite similar to those for TG2-based tests. ${ }^{10}$ A combination of the two tests appears to be slightly superior to either of the two tests alone, ${ }^{11-12}$ but at an increased cost.

Detection of antibodies to TG2 has been incorporated in three innovative test systems. (1) A point of contact test has been developed. ${ }^{13}$ The performance is very good, and the test is easy to use requiring only a drop of patient blood. Test documentation and interpretation of the results by lay people may however be problematic. (2) Serum IgA-TG2 antibodies represent a "spill-over" from the gut as the antibodies generally are meant for secretion into the bowel lumen, and because they first react with the TG2antigen present in the mucosa. Therefore, deposits of IgA anti-TG2 in their mucosa even in the presence of normal serum levels of the same antibody may be used for diagnosis, ${ }^{14}$ but requires that biopsies are snap-frozen in liquid nitrogen. This is rarely available in endoscopy units. (3) The IgA-TG2 antibodies are locally produced in the small intestinal mucosa. Challenge with gluten ex vivo will induce B cells within the biopsies to secrete IgA anti-TG2. These antibodies can be detected in culture supernatants. ${ }^{15}$ A diagnostic procedure based on the latter observation has failed to yet reach general acceptance.

\section{Detection of gluten specific $\mathrm{T}$ cells after gluten challenge}

Diagnosing celiac disease when the patient already has commenced a gluten-free diet, without proper diagnosis, can be difficult. Clinical signs, serology, and morphology will all return to normal with the diet. Standard current practice in these cases requires an oral gluten challenge over months. Many patients are reluctant to prolonged gluten challenge. Recent observations suggest that extended challenge may not be required. After oral gluten challenge for only 3 days, the majority of celiac patients appear to have T cells in their peripheral blood, which are specific for deamidated gluten peptides. Such T cells can be detected by ELISPOT ${ }^{16}$ or by staining with HLA-DQ2-gliadin peptide tetramers. ${ }^{17}$ How well these tests function in clinical settings remains to be established.

\section{HLA typing}

The great majority of the celiac disease patients carry the HLA-DQ2 variant DQ2.5. (DQA $\left.1^{\star} 05 / \mathrm{DQB1}{ }^{\star} 02\right)$ and most 
of the remaining patients are HLA-DQ8. The very few celiac disease patients who do not belong either of two above categories carry one of the two chains of the DQ2.5 heterodimer, i.e. they are DQA1 ${ }^{\star} 0201 / \mathrm{DQB1}{ }^{*} 02$ (DQ2.2) or they are $\mathrm{DQA}^{\star} 05 / \mathrm{DQB} 1^{\star} 0301$ (DQ7). The absence of $\mathrm{DQB} 1^{\star} 02$ is a strong negative predictor of the disease, and HLA typing can thus be used as a diagnostic aid. ${ }^{18}$ Detection of either DQ2.5 or DQ8 has however no clinical value as both DQ2.5 and DQ8 are very frequent in the normal population.

\section{ESTABLISHEDTREATMENT Gluten-free diet}

The gluten-free diet is the basis of all treatment of celiac disease and should be recommended to all patients once the diagnosis has been properly made. The gluten-free diet implicates a diet without wheat, rye barley, and all closely related cereals including spelt (a wheat variant). Oats is a related cereal that is tolerated by almost all celiacs, although sporadic cases of oat intolerance have been reported.
Many oat products for the general market are contaminated with other cereals. Other cereals are tolerated, including maize, rice, sorghum, and tef.

It has been very difficult to demonstrate a definite safe level threshold for gluten intake to celiacs that probably relate to the polygenic and mulifactorial nature of the disorder. It appears that a gluten amount in the range of $50-100 \mathrm{mg}$ per day is safe for most celiac disease patients. ${ }^{19}$ A completely gluten-free diet is difficult to achieve due to small levels of contamination in international trade bulk food products and the use of gluten in food industry. The use of wheat starch as basis of bread also adds some gluten to the total load, and wheat starch is "allowed" in some but not all countries. Beer is another source of gluten due to the content of proteins from malted barley.

\section{NOVEL THERAPEUTICS}

There is an unmet need for alternative treatments in celiac disease. The new insight in the pathogenesis has given a number of new targets for intervention. Several of the new therapies have reached clinical testing (Table 1).

Two of the therapies aim to prevent gluten from getting in touch with the mucosal immune system; either by oral supplementation of enzymes that will augment the breakdown of gluten to fragments that are no longer immunostimulatory ${ }^{20-21}$ or by adding a polymer that will sequester the gluten proteins. ${ }^{22}$ When it comes to the oral glutenase supplementation, two drugs are currently under development. ALV003 consists of a combination of a glutamine-specific cysteine protease (EP-B2) and a bacterial proline-specific prolyl endoprotease..$^{20}$ The two enzymes have gastric activity and act in concert. Another enzyme which is effective for breakdown of gluten and which also has gastric activity is a prolyl endoprotease from Aspergillus niger. ${ }^{21}$ Clinical trials for celiac disease are ongoing or will start soon for this class of compounds.

An approach that also targets the gluten antigen itself is to make modi-

Table 1 Potential new therapies for celiac disease

\begin{tabular}{|c|c|c|c|c|c|c|}
\hline Mode of action & Compound & Compound class & Manufacturer & Status & $\begin{array}{l}\text { ClinicalTrials. } \\
\text { gov identifier }\end{array}$ & References \\
\hline $\begin{array}{l}\text { Chemokine receptor } \\
\text { antagonist }\end{array}$ & CCX282-B (Traficet) & Small molecule & $\begin{array}{l}\text { ChemoCentryx, } \\
\text { USA }\end{array}$ & Phase II & NCT00540657 & \\
\hline Zonulin antagonist & $\begin{array}{l}\text { Larazotide acetate } \\
\text { (AT-1001) }\end{array}$ & Peptide & $\begin{array}{l}\text { Alba } \\
\text { Therapeutics, } \\
\text { USA }\end{array}$ & Phase II & $\begin{array}{l}\text { NCT00620451 } \\
\text { NCT00492960 }\end{array}$ & 23 \\
\hline Glutenase & $\begin{array}{l}\text { Aspergillus niger } \\
\text { prolyl endoprotease }\end{array}$ & Enzyme & $\begin{array}{l}\text { DSM, the } \\
\text { Netherlands }\end{array}$ & Preclinical & - & 21 \\
\hline Peptide vaccination & $\begin{array}{l}\text { Immunodominant } \\
\text { gluten peptides }\end{array}$ & Peptide & $\begin{array}{l}\text { Nexpep, } \\
\text { Australia }\end{array}$ & Preclinical & - & \\
\hline $\begin{array}{l}\text { Immune modulation } \\
\text { by hookworm }\end{array}$ & $\begin{array}{l}\text { Necator } \\
\text { americanus }\end{array}$ & Parasite & $\begin{array}{l}\text { Princess } \\
\text { Alexandra } \\
\text { Hospital, } \\
\text { Brisbane, } \\
\text { Australia }\end{array}$ & Phase II & NCT00671138 & \\
\hline $\begin{array}{l}\text { Transglutaminase } \\
\text { inhibition }\end{array}$ & $\begin{array}{l}\text { KCC009 } \\
\text { (Transglutaminase } \\
\text { inhibition) }\end{array}$ & Small molecule & - & Discovery & - & 26 \\
\hline HLA blockage & $\begin{array}{l}\text { HLA-DQ2 or HLA- } \\
\text { DQ8 blockers }\end{array}$ & - & - & Discovery & - & $28-29$ \\
\hline $\begin{array}{l}\text { Gluten sequestering } \\
\text { polymer }\end{array}$ & P(HEMA-co-SS) & Polymer & - & Discovery & - & 22 \\
\hline Anti-IL-15 & AMG-714 & Humanized mAb & Amgen, USA & Phase II in RA & NCT00433875 & \\
\hline
\end{tabular}

HLA, human leukocyte antigen; IL, interleukin; mAb, monoclonal antibody. 
fied grains that are devoid of immunostimulatory sequences. This can possibly be achieved by conventional breeding or more likely by genetically modified organism approaches. The large number of different peptide epitopes located in multiple classes of gluten proteins ( $\alpha$ - and $\gamma$-gliadins as well as glutenins), which are encoded in different loci in the wheat genome represents a challenge for this method to be successful.

Another strategy aims at correcting an epithelial barrier defect that is associated with celiac disease. An increased barrier leakage will lead to increased exposure to immunostimulatory gluten peptides as well as other compounds that may be involved for intestinal homeostasis. The zonulin inhibitor AT1001 is reducing gluten-induced barrier dysfunction, ${ }^{23}$ and this compound has entered phase II trials.

One can also envision treating celiac disease by hindering the activation of gluten reactive $\mathrm{CD} 4{ }^{+} \mathrm{T}$ cells. This can be achieved by preventing the formation of deamidated peptides, or by blocking the peptide-binding site of the gluten presenting HLA molecules DQ2 and DQ8. ${ }^{24}$ Discovery type of research is ongoing to develop drugs that will interfere with these processes. Several classes of TG2 inhibitors have been developed ${ }^{25-27}$ as well as peptide-like compounds that bind specifically to HLA-DQ2 and inhibit recognition of gluten peptides by T cells. ${ }^{28-29}$

The identification of gluten epitopes implicated in the $\mathrm{CD} 4^{+} \mathrm{T}$-cell response to gluten has also opened the possibility for peptide vaccination aiming at tolerizing the gluten reactive $\mathrm{T}$ cells. The identification of dominant epitopes to which there are responses in all celiac disease patients is an important step toward realizing this concept. However, for success, this approach will require the induction of tolerance to all epitopes (including those which are more infrequently recognized) by vaccination with a few immunodominant epitopes. This approach is expected to enter clinical trials soon.

There is also an ongoing phase II clinical trial in celiac disease aiming to test whether an intestinal hookworm infection will change the local immune response mode and suppress gluten sensitivity in people with celiac disease. If successful in celiac disease, this treatment is candidate for testing also in inflammatory bowel disease.

Therapy aiming at interference with cytokines has successfully been used for various autoimmune diseases, and a plethora of new therapeutic modalities in this field is under development. However, due to the low acceptance of side effects for the treatment of celiac disease, it is unlikely the celiac disease will be a primary indication for most of these therapies. Anti-IL15 therapy might an exception to this, as anti-IL15 treatment has been prospected as therapy for refractory celiac disease. If successful in refractory celiac disease, uncomplicated celiac disease might also become an indication.

\section{FINAL REMARKS}

Several new diagnostic tools for celiac disease have emerged and many aspects of the pathogenesis are well understood. Other aspects are less well perceived, and the identification of novel risk genes ${ }^{30}$ will likely increase our insights into the immune mechanism of this fascinating disorder. The treatment with gluten-free diet still stands as the only clinical option, but it can be envisaged that several new therapeutic options may be introduced in the near future.

C 2009 Society for Mucosal Immunology

\section{REFERENCES}

1. Sollid, L.M. Coeliac disease: dissecting a complex inflammatory disorder. Nat. Rev. Immunol. 2, 647-655 (2002).

2. Kagnoff, M.F. Celiac disease: pathogenesis of a model immunogenetic disease. J. Clin. Invest. 117, 41-49 (2007).

3. Rostom, A., Murray, J.A. \& Kagnoff, M.F. American Gastroenterological Association (AGA) institute technical review on the diagnosis and management of celiac disease. Gastroenterology 131, 1981-2002 (2006).

4. Collin, P., Huhtala, H., Virta, L., Kekkonen, L. \& Reunala, T. Diagnosis of celiac disease in clinical practice: physician's alertness to the condition essential. J. Clin. Gastroenterol. 41, 152-156 (2007).

5. Dieterich, W. et al. Identification of tissue transglutaminase as the autoantigen of celiac disease. Nat. Med. 3, 797-801 (1997).

6. Salmi, T.T. et al. Immunoglobulin A autoantibodies against transglutaminase 2 in the small intestinal mucosa predict forthcoming coeliac disease. Aliment. Pharmacol. Ther. 24, 541-552 (2006).

7. Kaukinen, K., Collin, P. \& Maki, M. Latent coeliac disease or coeliac disease beyond villous atrophy? Gut 56, 1339-1340 (2007).

8. Osman, A.A. et al. B cell epitopes of gliadin. Clin. Exp. Immunol. 121, 248-254 (2000).

9. Aleanzi, M., Demonte, A.M., Esper, C., Garcilazo, S. \& Waggener, M. Celiac disease: antibody recognition against native and selectively deamidated gliadin peptides. Clin. Chem. 47, 2023-2028 (2001).

10. Sugai, E. et al. Accuracy of testing for antibodies to synthetic gliadin-related peptides in celiac disease. Clin. Gastroenterol. Hepatol. 4, 1112-1117 (2006).

11. Kaukinen, K. et al. Resurrection of gliadin antibodies in coeliac disease. Deamidated gliadin peptide antibody test provides additional diagnostic benefit. Scand. J. Gastroenterol. 42, 1428-1433 (2007).

12. Rashtak, S., Ettore, M.W., Homburger, H.A. \& Murray, J.A. Combination testing for antibodies in the diagnosis of celiac disease: comparison of multiplex immunoassay and ELISA methods. Aliment. Pharmacol. Ther. 28, 805-813 (2008).

13. Raivio, T. et al. Self transglutaminase-based rapid coeliac disease antibody detection by a lateral flow method. Aliment. Pharmacol. Ther. 24, 147-154 (2006).

14. Salmi, T.T. et al. Endomysial antibody-negative coeliac disease: clinical characteristics and intestinal autoantibody deposits. Gut 55, 1746-1753 (2006).

15. Picarelli, A. et al. Production of antiendomysial antibodies after in-vitro gliadin challenge of small intestine biopsy samples from patients with coeliac disease. Lancet 348, 1065-1067 (1996).

16. Anderson, R.P., Degano, P., Godkin, A.J., Jewell, D.P. \& Hill, A.V. In vivo antigen challenge in celiac disease identifies a single transglutaminase-modified peptide as the dominant A-gliadin T-cell epitope. Nat. Med. 6, 337-342 (2000).

17. Ráki, M. et al. Tetramer visualization of guthoming gluten-specific T cells in the peripheral blood of celiac disease patients. Proc. Natl. Acad. Sci. USA 104, 2831-2836 (2007).

18. Sollid, L.M. \& Lie, B.A. Celiac disease genetics: current concepts and practical applications. Clin. Gastroenterol. Hepatol. 3, 843-851 (2005).

19. Stern, M. et al. Analysis and clinical effects of gluten in coeliac disease. Eur. J. Gastroenterol. Hepatol. 13, 741-747 (2001).

20. Gass, J., Bethune, M.T., Siegel, M., Spencer, A. \& Khosla, C. Combination enzyme therapy for gastric digestion of dietary gluten in patients with celiac sprue. Gastroenterology 133, 472-480 (2007).

21. Stepniak, D. et al. Highly efficient gluten degradation with a newly identified prolyl endoprotease: implications for celiac disease. Am. J. Physiol Gastrointest. Liver Physiol. 291, G621-G629 (2006).

22. Pinier, M. et al. Polymeric binders suppress gliadin-induced toxicity in the intestinal epithelium. Gastroenterology doi:10.1053/j. gastro.2008.09.016.

23. Paterson, B.M., Lammers, K.M., Arrieta, M.C., Fasano, A. \& Meddings, J.B. The safety, tolerance, pharmacokinetic and pharmacodynamic effects of single doses of 
AT-1001 in coeliac disease subjects: a proof of concept study. Aliment. Pharmacol. Ther. 26, 757-766 (2007).

24. Sollid, L.M. \& Khosla, C. Future therapeutic options for celiac disease. Nat. Clin. Pract. Gastroenterol. Hepatol. 2, 140-147 (2005).

25. Hausch, F., Halttunen, T., Maki, M. \& Khosla, C. Design, synthesis, and evaluation of gluten peptide analogs as selective inhibitors of human tissue transglutaminase. Chem. Biol. 10, 225-231 (2003).
26. Choi, K. et al. Chemistry and biology of dihydroisoxazole derivatives: selective inhibitors of human transglutaminase 2. Chem. Biol. 12, 469-475 (2005).

27. Pardin, C., Pelletier, J.N., Lubell, W.D. \& Keillor, J.W. Cinnamoyl inhibitors of tissue transglutaminase. J. Org. Chem. 73, 5766-5775 (2008).

28. Xia, J. et al. Cyclic and dimeric gluten peptide analogues inhibiting DQ2-mediated antigen presentation in celiac disease. Bioorg. Med. Chem. 15, 6565-6573 (2007).
29. Kapoerchan, V.V. et al. Design of azidoproline containing gluten peptides to suppress CD4+ T-cell responses associated with celiac disease. Bioorg. Med. Chem. 16, 2053-2062 (2008).

30. Hunt, K.A. et al. Newly identified genetic risk variants for celiac disease related to the immune response. Nat. Genet. 40, 395-402 (2008). 